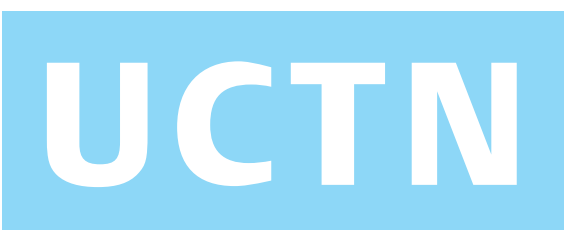

\title{
Pulmonary embolism after sclerotherapy treatment for variceal bleeding
}

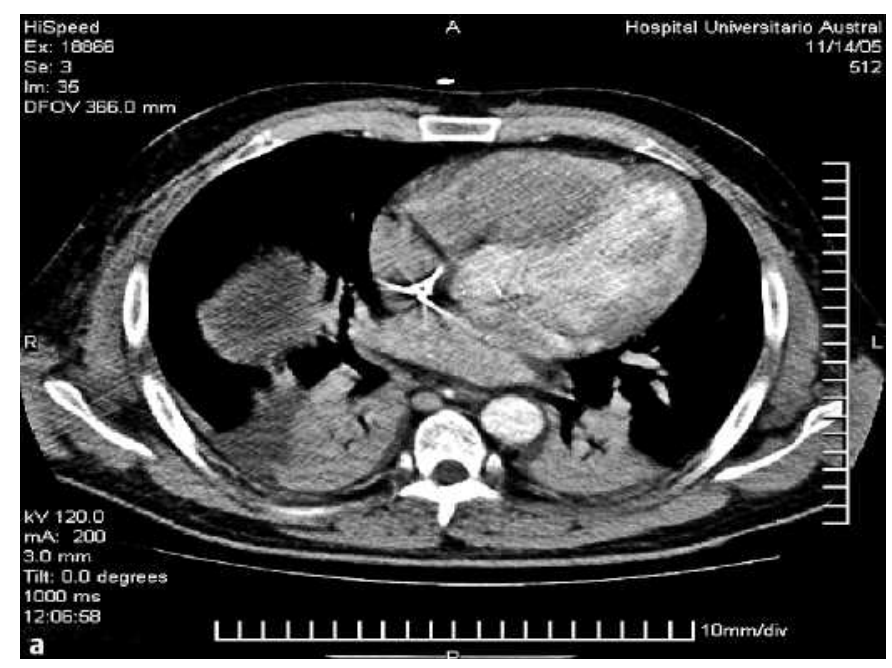

Figure 1 a, b Helical computed tomography, showing no signs of thrombus in the main pulmonary arteries. Bilateral atelectasis and pleural effusions are present.

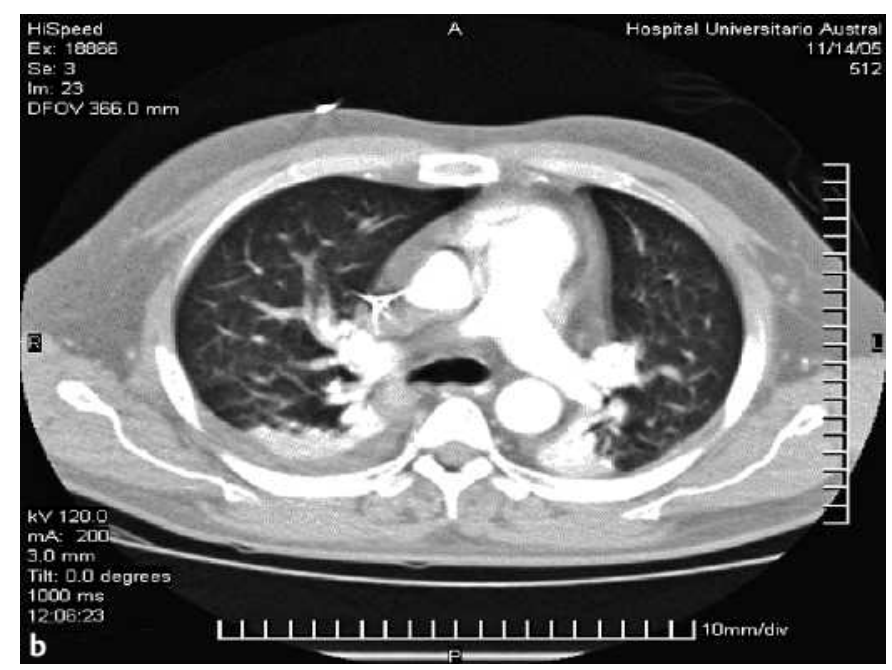

A 51-year-old man presented to the emergency department with upper gastrointestinal bleeding. He had a history of portal hypertension and cirrhosis. On admission, he was lucid and stable.

His only abnormal laboratory finding was a hematocrit of 27.3. An emergency endoscopy was performed. Active variceal bleeding was found, and $4 \mathrm{ml}$ of $4 \%$ poli- docanol (Aethoxysclerol) was injected into the varix, which stopped the bleeding. The patient was then started on prophylactic octreotide and ciprofloxacin treatment. Thirty hours after the procedure, the patient developed fever, tachycardia, tachypnea, and hypoxemia, requiring intubation and mechanical ventilation. The patient remained on mechanical ventilation, and the clinical course was complicated with pneumonia. Due to persistent hypoxemia requiring high fractions of inspired oxygen on hospital day 25 , thoracic computed tomography was then performed (Figure 1), as well as pulmonary angiography (Figure 2). No thrombus formation was found in the inferior cava or main pulmonary arteries, but bilateral basal peripheral microemboli were found.

The patient remained on mechanical ventilation for 40 days before the oxygenation parameters normalized. He was extubated and discharged.

Complications of sclerotherapy such as fever and pain are common. Pulmonary complications have an incidence of $5 \%$; the most common cause is aspiration pneumonia, followed by respiratory distress [1-4]. Polidocanol embolism has rarely been described in the literature. This type of complication may be related to factors such as the volume of the injected material, the area treated, and the use of repeated injections [4]. No specific treatment has been described for pulmonary embolism by polidocanol, and therapy is limited to respiratory support. This case highlights an unusual and potentially devastating complication of sclerotherapy.

Endoscopy_UCTN_Code_CPL_1AH_2AC

\section{J. C. Escardo, S. J. Cosenza, J. H. Alvarez, P. Pratesi, G. G. Parra, A. Hita}

Intensive Care Unit, Austral University Hospital, Pilar, Argentina. 


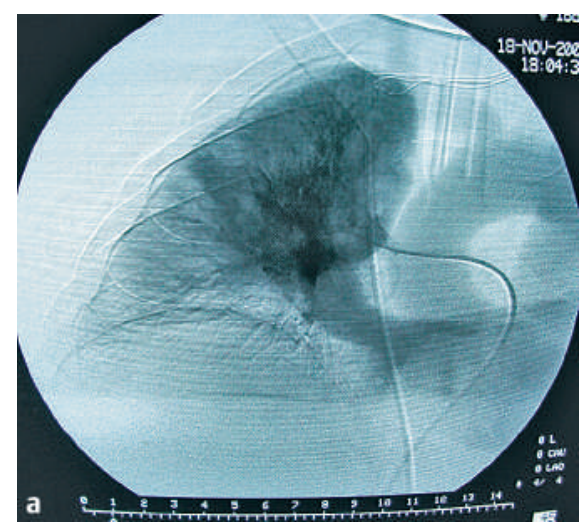

\section{References}

${ }^{1}$ Lee JY, Moon SH, Lee SM et al. A case of noncardiogenic pulmonary edema by ethanolamine oleate. Korean J Intern Med 1994; 9: $125-127$

${ }^{2}$ Witthoft T, Homann N, Dodt C, Ludwig D. Massive pulmonary embolism after endoscopic therapy for gastric variceal bleeding. Z Gastroenterol 2004; 42: 383-386

${ }^{3}$ Nassif A, Coevoet V, Resten A et al. Pulmonary embolization from migration of sclerotherapy material. J Radiol 2001; 82: $583-$ 585

${ }^{4}$ Kok K, Bond RP, Duncan IC et al. Distal embolization and local vessel wall ulceration after gastric variceal obliteration with $\mathrm{N}$-butyl-2cyanoacrylate: a case report and review of the literature. Endoscopy 2004; 36: $442-$ 446

\section{Corresponding author}

\section{J. C. Escardo, M.D.}

Intensive Care Unit Hospital Universitario Austral Presidente Perón 1500

Pilar 1629

Argentina

Fax: $\quad+54-1-2322-482883$

Email: juanxescardo@gmail.com

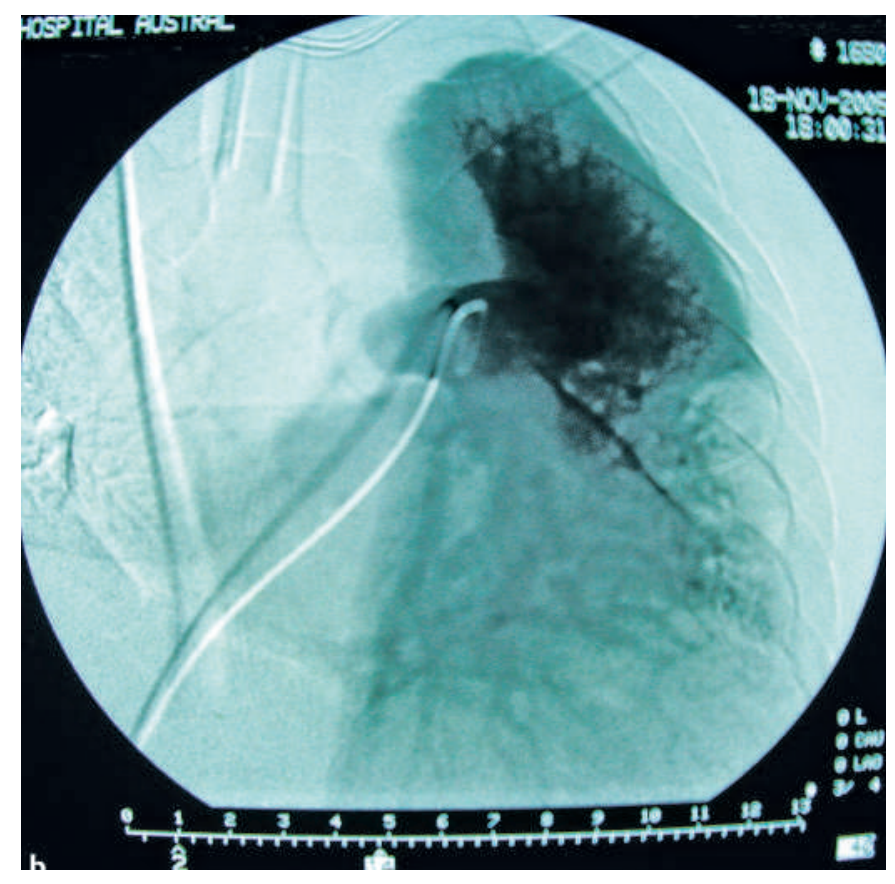

Figure $\mathbf{2}$ a, b The absence of contrast in the inferior branches of the subsegmentary pulmonary arteries should be noted. 